\title{
Acute clinical grading in pediatric severe traumatic brain injury and its association with subsequent intracranial pressure, cerebral perfusion pressure, and brain oxygenation
}

\author{
Anthony A. Figaji, F.C.S., ${ }^{1,2}$ Eugene Zwane, Ph.D. ${ }^{3}$ A. Graham Fieggen, F.C.S., ${ }^{1,2}$ \\ Jonathan C. Peter, F.C.S., ${ }^{1}$ And Peter D. LeRoux, M.D. ${ }^{4}$ \\ Divisions of ${ }^{1}$ Neurosurgery and ${ }^{2}$ Pediatric Neuroscience, School of Child and Adolescent Health, \\ Institute for Child Health, University of Cape Town, Red Cross Childrens Hospital, Rondebosch, \\ Cape Town, South Africa; ${ }^{3}$ Infectious Disease Epidemiology Unit (Biostatistics), \\ School of Public Health and Family Medicine, University of Cape Town; ${ }^{4}$ Department of Neurosurgery, \\ Hospital of the University of Pennsylvania, Philadelphia, Pennsylvania
}

\begin{abstract}
Object. The goal of this paper was to examine the relationship between methods of acute clinical assessment and measures of secondary cerebral insults in severe traumatic brain injury in children.

Methods. Patients who underwent intracranial pressure (ICP), cerebral perfusion pressure (CPP), and brain oxygenation $\left(\mathrm{PbtO}_{2}\right)$ monitoring and who had an initial Glasgow Coma Scale score, Pediatric Trauma Score, Pediatric Index of Mortality 2 score, and CT classification were evaluated. The relationship between these acute clinical scores and secondary cerebral insult measures, including ICP, CPP, $\mathrm{PbtO}_{2}$, and systemic hypoxia were evaluated using univariate and multivariate analysis.

Results. The authors found significant associations between individual acute clinical scores and select physiological markers of secondary injury. However, there was a large amount of variability in these results, and none of the scores evaluated predicted each and every insult. Furthermore, a number of physiological measures were not predicted by any of the scores.

Conclusions. Although they may guide initial treatment, grading systems used to classify initial injury severity appear to have a limited value in predicting who is at risk for secondary cerebral insults.
\end{abstract}

(DOI: 10.3171/FOC.2008.25.10.E4)

\section{KEY WoRds - brain oxygenation - cerebral perfusion pressure • clinical assessment • Glasgow Coma Scale • secondary insult • traumatic brain injury}

I $\mathrm{N}$ pediatric patients who have experienced trauma, clinical assessment and clinical grading at admission can be used to guide treatment protocols and to predict outcome. ${ }^{3}$ In large part, these various grading systems, for example, the GCS, ${ }^{13}$ PTS,${ }^{28}$ PIM2, ${ }^{26}$ pupillary reactivity, ${ }^{30}$ and brain CT classification, ${ }^{14}$ are associated with the severity of the patient's primary injury. However, outcome after severe TBI is affected also by secondary cerebral injury that evolves during the days after the initial primary insult. Therefore, current treatment of a child with severe TBI in the PICU attempts to avoid or ameliorate secondary cerebral injury.

Common secondary cerebral insults in TBI that are associated with adverse outcomes include elevated ICP,

\footnotetext{
Abbreviations used in this paper: $\mathrm{CPP}=$ cerebral perfusion pressure; $\mathrm{FiO}_{2}=$ fraction of inspired $\mathrm{O}_{2} ; \mathrm{GCS}=$ Glasgow Coma Scale; ICP = intracranial pressure; MABP = mean arterial blood pressure; $\mathrm{PbtO}_{2}=$ brain $\mathrm{O}_{2}$ tension; $\mathrm{PICU}=$ pediatric intensive care unit; PIM2 = Pediatric Index of Mortality, revised version; PTS = Pediatric Trauma Score; $\mathrm{SaO}_{2}=$ saturation of $\mathrm{O}_{2} ; \mathrm{TBI}=$ traumatic brain injury.
}

reduced CPP, hypotension, systemic hypoxia, and brain hypoxia. ${ }^{2,4-6,8,10,11,18,21,22,24,27,29,31}$ These and other secondary insults, although potentially avoidable, are common and may contribute to death in as many as $42 \%$ of children who die after admission for head injury. ${ }^{23}$ The relationship between outcome and the various grading or scoring systems used to classify pediatric patients who have suffered trauma is well described. However, the relationship between these grading systems of injury and the likelihood of secondary insults is less well defined.

In this study we sought to examine the relationship between acute measures of injury severity on admission and the subsequent development of secondary cerebral insults in children with severe TBI after admission to the PICU.

\section{Methods}

Ethics approval for the study was obtained from the institutional review boards of the Red Cross Children's Hospital and the University of Cape Town. 


\section{A. A. Figaji et al.}

TABLE 1: Admission demographic and clinical variables

\begin{tabular}{lc}
\hline \multicolumn{1}{c}{ Category } & No. of Patients* \\
\hline age (range) & $\begin{array}{c}6.5 \pm 3.4 \text { yrs }(9 \\
\text { mos-14 yrs) }\end{array}$ \\
initial GCS score & \\
3 & 5 \\
4 & 9 \\
5 & 12 \\
6 & 10 \\
7 & 11 \\
8 & 5 \\
median GCS motor component score (range) & $3(1-5)$ \\
pupil reaction & \\
bilat reactive & 41 \\
unilat nonreactive & 5 \\
bilat nonreactive & 6 \\
PTS & $3 \pm 1.4$ \\
PIM2 score & $0.16 \pm 0.2$ \\
CT classification & \\
I & 3 \\
II & 31 \\
III & 13 \\
IV & 3 \\
evacuated mass lesion & 2 \\
nonevacuated mass lesion & 0 \\
\hline & \\
\hline & \\
\hline & \\
&
\end{tabular}

* Unless stated otherwise.

\section{Patient Selection}

Clinical and physiological data were retrospectively obtained from a larger prospective observational study of severe TBI in children at Red Cross Children's Hospital. Patients were included in this study if they met the following criteria: 1) they underwent continuous ICP, CPP, and $\mathrm{PbtO}_{2}$ monitoring; and 2) the initial injury was classified according to the GCS, motor component of the GCS, PTS, PIM2, pupil reactivity, and the Marshall CT classification of head injury. Each of these grades had to be recorded for a patient to be included in the study.

\section{Grading of TBI Severity at Patient Admission}

Glasgow Coma Scale. Postresuscitation GCS score (pediatric coma score for preverbal children) was recorded in all patients. The motor component of the GCS was separately documented.

Pediatric Trauma Score. The PTS includes 6 variables: weight, systolic blood pressure, mental status, airway maintenance, skeletal injury, and open wounds. ${ }^{28}$

Pediatric Index of Mortality. The PIM2 uses the following PICU admission variables to predict outcome:26 systolic blood pressure, pupillary reaction (fixed or reactive), $\mathrm{PaO}_{2} / \mathrm{FiO}_{2}$ ratio, base excess, elective admission (yes/no), mechanical ventilation (yes/no), recovery from
TABLE 2: Summary of physiological variables for all patients*

\begin{tabular}{|c|c|}
\hline Category & Value \\
\hline $\mathrm{mlCP}_{24}$ & $16.5 \pm 11 \mathrm{~mm} \mathrm{Hg}$ \\
\hline $\mathrm{mlCP}_{\text {total }}$ & $14.8 \pm 9.3 \mathrm{~mm} \mathrm{Hg}$ \\
\hline $\mathrm{ICP}_{\text {peak }}$ & $34.6 \pm 17.4 \mathrm{~mm} \mathrm{Hg}$ \\
\hline ICP >20 mm Hg & $17.9 \pm 24.8 \mathrm{hrs}$ \\
\hline $\mathrm{mlCP}>20 \mathrm{~mm} \mathrm{Hg}$ & $22.3 \pm 13.4 \mathrm{~mm} \mathrm{Hg}$ \\
\hline $\mathrm{CPP}_{\text {low }}$ & $40.2 \pm 15.9 \mathrm{~mm} \mathrm{Hg}$ \\
\hline $\begin{array}{l}\text { median (IQR) no. of hrs at CPP } \\
<40 \mathrm{~mm} \mathrm{Hg}\end{array}$ & $0(0-2)$ \\
\hline $\begin{array}{l}\text { median (IQR) no. of hrs at CPP } \\
<50 \mathrm{~mm} \mathrm{Hg}\end{array}$ & $3(0-12)$ \\
\hline $\begin{array}{l}\text { median (range) no. of episodes of } \\
\mathrm{PaO}_{2}<60 \mathrm{~mm} \mathrm{Hg}\end{array}$ & $0(0-16)$ \\
\hline lowest $\mathrm{PaO}_{2}$ & $87 \pm 44 \mathrm{~mm} \mathrm{Hg}$ \\
\hline $\begin{array}{l}\text { median (range) no. of episodes } \\
\mathrm{SaO}_{2}<90 \%\end{array}$ & $0(0-9)$ \\
\hline lowest $\mathrm{PbtO}_{2}$ & $11.2 \pm 7.4 \mathrm{~mm} \mathrm{Hg}$ \\
\hline $\mathrm{mPbtO}_{2} 24$ & $28.4 \pm 11.5 \mathrm{~mm} \mathrm{Hg}$ \\
\hline $\begin{array}{l}\text { median (range) no. of hrs at } \mathrm{PbtO}_{2} \\
5 \mathrm{~mm} \mathrm{Hg}\end{array}$ & $0(0-20)$ \\
\hline $\begin{array}{l}\text { median (range) no. of hrs at } \mathrm{PbtO}_{2} \\
<10 \mathrm{~mm} \mathrm{Hg}\end{array}$ & $1(0-22)$ \\
\hline
\end{tabular}

surgery (yes/no), cardiac bypass (yes/no), and high risk/ low risk diagnosis.

Pupil Reactivity. In this study, postresuscitation pupillary reactions were classified as bilaterally reactive (1), unilaterally nonreactive (2), or bilaterally nonreactive (3). The influence of medications was excluded.

Head CT Classification. The severity of TBI was classified according to the Marshall system ${ }^{14}$ based on head CT scan findings at admission. The grades include the following: diffuse injury Score I (normal scan), II (abnormal scan with open cisterns), III (effaced or obliterated cisterns), or IV (midline shift $>5 \mathrm{~mm}$ ); evacuated mass lesion; and lesion $>25 \mathrm{~cm}^{3}$ not surgically evacuated.

Patient Age. Age also was used in this study to classify patient risk given that age may influence outcome ${ }^{9,17}$ and physiological thresholds. ${ }^{4}$

\section{Physiological Monitoring}

The $\mathrm{PbtO}_{2}, \mathrm{ICP}, \mathrm{CPP}$, and pulse oximetry $\left(\mathrm{SaO}_{2}\right)$ were monitored continuously and recorded hourly. The CPP was calculated as the difference between MABP and $\mathrm{ICP}(\mathrm{CPP}=\mathrm{MABP}-\mathrm{ICP})$. The $\mathrm{PbtO}_{2}$ catheter $(\mathrm{LICOX}$, Integra Neuroscience) was placed $2.5 \mathrm{~cm}$ below the cortical surface into right frontal lobe white matter that appeared normal on the head CT scan. The $\mathrm{PbtO}_{2}$ monitor function and stability were confirmed by an appropriate $\mathrm{PbtO}_{2}$ increase following an $\mathrm{O}_{2}$ challenge. A follow-up 


\section{Acute clinical scores and secondary cerebral insults in children}

head CT scan was obtained in each patient to confirm correct placement of the monitor.

\section{Management of ICP, CPP, and $\mathrm{PbtO}_{2}$}

All patients were resuscitated and underwent endotracheal intubation and mechanical ventilation. Each patient was treated in the PICU according to a local algorithm consistent with the Guidelines for the Management of Severe Pediatric TBI. ${ }^{1}$ In general, a minimum CPP target of $50 \mathrm{~mm} \mathrm{Hg}$ was set for patients and test elevation of CPP was performed if the $\mathrm{PbtO}_{2}$ was $<20 \mathrm{~mm} \mathrm{Hg}$. Compromised (low) $\mathrm{PbtO}_{2}$ was defined as $<20 \mathrm{~mm} \mathrm{Hg}$ and was treated using a hierarchical treatment algorithm in a cause-directed fashion. In general, this meant attempting to identify a possible cause for the reduction in $\mathrm{PbtO}_{2}$ and more aggressively treating abnormal or borderline values for ICP, CPP, low $\mathrm{PaCO}_{2}$, low arterial saturation/low $\mathrm{PaO}_{2}$, and low hemoglobin. The following specific measures were used, depending on ICP, MABP, $\mathrm{PaO}_{2}$, hemoglobin, transcranial Doppler flow velocities and status of autoregulation (when known), and $\mathrm{PaCO}_{2}$ : 1) elevated ICP was treated more aggressively if present; 2) the patient's blood pressure was elevated to test $\mathrm{PbtO}_{2}$ at a higher CPP with volume infusion and/or inotropic support unless impaired autoregulation caused concomitant increases in ICP with elevated blood pressure; 3) higher $\mathrm{PaCO}_{2}$ was tolerated to induce cerebral vasodilation if ICP was not elevated; 4) a lower threshold for blood transfusion was used to increase hemoglobin to $10 \mathrm{~g} / \mathrm{dl}$ or more; and 5) the $\mathrm{FiO}_{2}$ was increased as an emergency temporary measure or if $\mathrm{PbtO}_{2}$ remained low despite optimization of the above parameters.

\section{Secondary Cerebral Insults}

The following secondary cerebral insults were evaluated in this study: elevated ICP, reduced CPP, compromised $\mathrm{PbtO}_{2}$, and systemic hypoxia. Physiological data were collated from hourly observations of continuously monitored ICP, CPP, $\mathrm{PbtO}_{2}$, and peripheral $\mathrm{SaO}_{2}$. In addition, all arterial blood gas samples were evaluated. Values considered abnormal were in keeping with recently published guidelines. $^{1}$

Intracranial Pressure. The following ICP values were calculated and recorded for each patient as: mean ICP during the first 24 hours $\left(\mathrm{mICP}_{24}\right)$, mean ICP for the full duration of monitoring $\left(\mathrm{mICP}_{\text {total }}\right)$, number of episodes of $\mathrm{ICP}>20 \mathrm{~mm} \mathrm{Hg}$, mean value for all $\mathrm{ICP}$ readings $>20$ $\mathrm{mm} \mathrm{Hg}(\mathrm{mICP}>20 \mathrm{~mm} \mathrm{Hg})$, and highest ICP $\left(\mathrm{ICP}_{\text {peak }}\right)$.

Cerebral Perfusion Pressure. The CPP insults were calculated for each patient as the lowest $\mathrm{CPP}\left(\mathrm{CPP}_{\text {low }}\right)$ and the number of episodes of CPP $<40$ and CPP $<50 \mathrm{~mm}$ $\mathrm{Hg}$.

Brain $\mathrm{O}_{2}$ Tension. The following $\mathrm{PbtO}_{2}$ values were calculated for each patient: minimum $\mathrm{PbtO}_{2}$ recorded during the patient's hospital course, mean $\mathrm{PbtO}_{2}$ during the first 24 hours $\left(\mathrm{mPbtO}_{2} 24\right)$, and the number of episodes of $\mathrm{PbtO}_{2}<10$ or $<5 \mathrm{~mm} \mathrm{Hg}$.

Systemic Hypoxia. Systemic hypoxia was defined as
$\mathrm{PaO}_{2}<60 \mathrm{~mm} \mathrm{Hg}$ on arterial blood gas measurement, or arterial $\mathrm{SaO}_{2}<90 \%$ on peripheral oximetry or arterial blood gas. In addition the lowest $\mathrm{PaO}_{2}$ observed also was recorded.

\section{Treatment Variables}

To supplement our evaluation of the relationship between initial grading and secondary cerebral insults we also examined whether a patient received one of the following treatments: hypertonic saline, use of inotropes, blood transfusion, and decompressive craniectomy.

\section{Statistical Analysis}

The individual acute clinical scores and head CT classification recorded in each patient were evaluated as independent variables and subsequent physiological parameters as dependent variables. Spearman correlation coefficients were used to determine relationships between scores and physiological variables. For categorical scores, the Pearson chi-square test was used for relationships with categorical variables and Kruskal-Wallis for continuous variables. The Kruskal-Wallis test evaluates equivalence between 2 medians while ignoring the ordering in the categorical covariates. The Pearson chi-square test was used to test the frequency distribution of categories within the individual scores. Scores that were significant in univariate analysis were entered into a multivariate analysis model. Significance was set at a probability level $=0.05$. Data are reported as means \pm SD or medians (interquartile range and/or range).

\section{Results}

\section{Clinical Characteristics}

Fifty-two pediatric patients with severe TBI who were monitored for ICP, CPP, and $\mathrm{PbtO}_{2}$ between June 2006 and May 2008 were included in the study. Demographic, clinical, and physiological data are summarized in Table 1 . All children were $<15$ years old. The distribution within age groups was as follows: $0-3$ years $(27.9 \%)$, 4-7 years $(38.5 \%), 8-11$ years $(30.8 \%)$, and $12-14$ years (3.8\%). The mechanism of injury was motor vehicle accident-related in $40(76.9 \%)$, crush injury in $3(5.8 \%)$, gunshot wound in 4 (7.7\%), blunt assault in $2(3.8 \%)$, fall from a height in $1(1.9 \%)$, stab to the head in $1(1.9 \%)$, and nonaccidental injury (shaken baby syndrome) in 1 (1.9\%). The initial systolic blood pressure was $<90 \mathrm{~mm} \mathrm{Hg}$ in 13 patients $(25 \%)$, and initial systemic hypoxia $\left(\mathrm{SaO}_{2}<90 \%\right.$ or $\mathrm{PaO}_{2}<60 \mathrm{~mm} \mathrm{Hg}$ ) was documented in 14 (26.9\%). Physiological variables for all patients after admission to the PICU are summarized in Table 2.

\section{Univariate Analysis}

Glasgow Coma Score. The postresuscitation GCS score was significantly associated with lowest CPP ( $\mathrm{p}=$ 0.004), CPP < $40 \mathrm{~mm} \mathrm{Hg}$ ( $\mathrm{p}=0.017), \mathrm{CPP}<50 \mathrm{~mm} \mathrm{Hg}$ (p $=0.019), \mathrm{PbtO}_{2}<5 \mathrm{~mm} \mathrm{Hg}(\mathrm{p}=0.008)$ (Fig. 1), and $\mathrm{PbtO}_{2}$ $<10 \mathrm{~mm} \mathrm{Hg}(\mathrm{p}=0.045)$. There were no associations with 


\section{A. A. Figaji et al.}

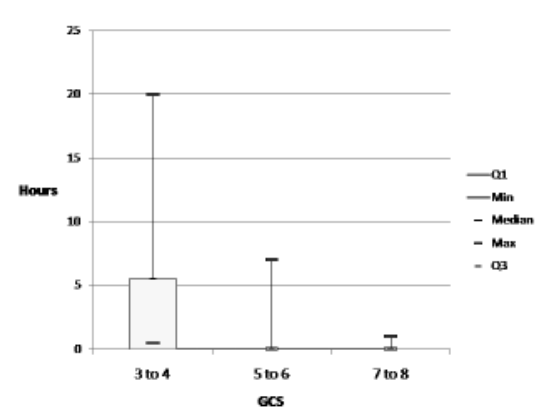

FIG. 1. Graph showing the initial GCS and episodes of $\mathrm{PbtO}_{2}<5$ $\mathrm{mm} \mathrm{Hg}$. The GCS scores are grouped in 3 categories: Score 3-4 (14 patients), Score 5-6 (22 patients), and Score 7-8 (16 patients), with the respective frequencies of episodes of $\mathrm{PbtO}_{2}<5 \mathrm{~mm} \mathrm{Hg}$ shown for each. Q1 = first quartile; Q3 = third quartile.

any other physiological or treatment variables, including the indices of elevated ICP.

Motor Component of the GCS. The motor response score of the GCS had no significant relationship with any variables when using the Spearman correlation coefficient. However, when the data were examined using the Kruskal-Wallis test a marginal relationship with $\mathrm{PbtO}_{2}<$ $5 \mathrm{~mm} \mathrm{Hg}(\mathrm{p}=0.046)$ and $\mathrm{PbtO}_{2}<10 \mathrm{~mm} \mathrm{Hg}(\mathrm{p}=0.047)$ was observed.

Pediatric Index of Mortality 2. The PIM2 score was associated with $\mathrm{CPP}<40 \mathrm{~mm} \mathrm{Hg}(\mathrm{p}=0.008), \mathrm{mICP}>20$ $\mathrm{mm} \mathrm{Hg}(\mathrm{p}=0.0013)$, and $\mathrm{ICP}_{\text {peak }}(\mathrm{p}<0.0001)$.

Pediatric Trauma Score. The PTS had a weak relationship with $\mathrm{PbtO}_{2}<10 \mathrm{~mm} \mathrm{Hg}(\mathrm{p}=0.046)$, but not with any other variables.

Pupil Reactivity on Admission. Pupil reactivity was associated with lowest CPP ( $\mathrm{p}=0.003), \mathrm{CPP}<40 \mathrm{~mm} \mathrm{Hg}$ ( $\mathrm{p}=0.024), \mathrm{CPP}<50 \mathrm{~mm} \mathrm{Hg}(\mathrm{p}=0.032), \mathrm{PbtO}_{2}<5 \mathrm{~mm}$ $\mathrm{Hg}(\mathrm{p}=0.026)$, and $\mathrm{PbtO}_{2}<10 \mathrm{~mm} \mathrm{Hg}(\mathrm{p}=0.031)$.

Computed Tomography Classification. Individual categories according to admission head CT scan findings demonstrated relationships with $\mathrm{mICP}>20 \mathrm{~mm} \mathrm{Hg}$ ( $\mathrm{p}=$ 0.017), and lowest CPP $(\mathrm{p}=0.006), \mathrm{PaO}_{2}<60 \mathrm{~mm} \mathrm{Hg}$ $(\mathrm{p}=0.029)$, and $\mathrm{SaO}_{2}<90 \%(\mathrm{p}=0.023)$. Decompressive craniectomy $(p=0.008)$ also was associated with individual Marshall categories. When the various CT categories were dichotomized to Scores I \& II and Scores III \& $\mathrm{IV}$, the following associations were observed: $\mathrm{mICP}_{24}(\mathrm{p}$ $=0.027)$, lowest CPP $(\mathrm{p}=0.003)$ (Fig. 2), CPP $<50 \mathrm{~mm}$ $\mathrm{Hg}(\mathrm{p}=0.015)$, and $\mathrm{mICP}_{\text {total }}(\mathrm{p}=0.046)$. The distribution of observations within the categories of the classification was significantly different; most patients demonstrated Score II and III changes on the initial head CT (44 of 52 patients).

Patient Age. Age was significantly associated with the following: lowest CPP ( $\mathrm{p}=0.007), \mathrm{CPP}<40 \mathrm{~mm} \mathrm{Hg}$ $(\mathrm{p}=0.001)$, and $\mathrm{CPP}<50 \mathrm{~mm} \mathrm{Hg}(\mathrm{p}=0.002)$ but with no other variables.

\section{Treatment Variables}

Head CT classification was significantly associated

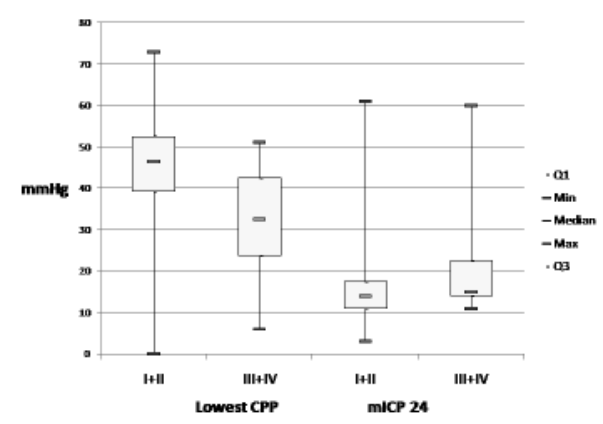

FIG. 2. Graph showing the relationship between CT classification (only diffuse injury Scores I \& II compared with Scores III \& IV; 50 patients) and lowest CPP and mean ICP for the first 24 hours (mICP 24). The 2 patients with evacuated mass lesions were excluded.

with craniectomy $(\mathrm{p}=0.015)$ (more patients with diffuse injury Scores III and IV received craniectomy). Pupil reactivity demonstrated a trend toward a significant association with craniectomy $(\mathrm{p}=0.056)$ and thiopentone $(p=0.073)$. No other scores demonstrated any other associations with treatment variables.

\section{Multivariate Analysis}

Variables found to be significantly associated with secondary cerebral insults were entered into multivariate analysis. These results are summarized in Table 3. The PIM2 score was associated with $\mathrm{mICP}>20 \mathrm{~mm} \mathrm{Hg} \mathrm{(p} \mathrm{=}$ $0.001), \mathrm{ICP}_{\text {peak }}(\mathrm{p}<0.0001)$, and $\mathrm{CPP}<40 \mathrm{~mm} \mathrm{Hg}(\mathrm{p}=$ $0.001)$. Initial GCS was associated with lowest CPP (p = $0.016)$ and $\mathrm{PbtO}_{2}<5 \mathrm{~mm} \mathrm{Hg}(\mathrm{p}=0.017)$. Pupil reactivity was associated with lowest $\mathrm{PbtO}_{2}(\mathrm{p}=0.039)$ and had a trend toward an association with lowest CPP $(\mathrm{p}=0.057)$, $\mathrm{CPP}<40(\mathrm{p}=0.073), \mathrm{PbtO}_{2}<5 \mathrm{~mm} \mathrm{Hg}(\mathrm{p}=0.076)$, and $\mathrm{PbtO}_{2}<10 \mathrm{~mm} \mathrm{Hg}(\mathrm{p}=0.057)$. Age was associated with lowest CPP (p < 0.0001), CPP < $40 \mathrm{~mm} \mathrm{Hg}(\mathrm{p}=0.004)$, and $\mathrm{CPP}<50 \mathrm{~mm} \mathrm{Hg}(\mathrm{p}<0.0001)$. There were no scores that had significant associations with ICP $>20 \mathrm{~mm} \mathrm{Hg}$, $\mathrm{mICP}_{24}, \mathrm{mICP}_{\text {total }}, \mathrm{PaO}_{2}<60 \mathrm{~mm} \mathrm{Hg}$, lowest $\mathrm{PaO}_{2}$, and $\mathrm{SaO}_{2}<90 \%$. No significant associations between PTS, CT classification, or motor component of the GCS and any of the measured variables were found in multivariate analysis. There were no significant associations between scores and treatment variables in multivariate analysis.

\section{Discussion}

In this study we examined 52 children with severe TBI and evaluated the relationship between acute scores of injury severity-including postresuscitation GCS score, PIM2, PTS, CT classification, pupil reactivity and age - and subsequent secondary cerebral insults, in particular elevated ICP, reduced CPP, compromised brain $\mathrm{O}_{2}$, and systemic hypoxia. None of the scoring systems had a consistent relationship with all potential secondary insults, and the strength of the association with different measures of secondary cerebral insults differed between the different scores. These results suggest that although acute grading systems may help predict outcome, they 
TABLE 3: Multivariate analysis showing the associations between scores and physiological measures with significant relationships or trends*

\begin{tabular}{|c|c|c|}
\hline $\begin{array}{c}\text { Physiological } \\
\text { Category }\end{array}$ & $\begin{array}{l}\text { Predictive Score } \\
\qquad(p \text { Value })\end{array}$ & $\begin{array}{c}\text { Regression } \\
\text { Estimate }(95 \% \mathrm{Cl})\end{array}$ \\
\hline \multicolumn{3}{|l|}{ ICP } \\
\hline ICP >20 mm Hg & none & \\
\hline mICP >20 mm Hg & PIM2 (0.001) & $29.2(12.5-46) \dagger$ \\
\hline $\mathrm{ICP}_{\text {peak }}$ & PIM2 (<0.0001) & $43.8(22.9-64.7) \dagger$ \\
\hline $\mathrm{mlCP}_{24}$ & none & \\
\hline $\mathrm{mICP}_{\text {total }}$ & none & \\
\hline \multicolumn{3}{|l|}{ CPP } \\
\hline \multirow[t]{3}{*}{ lowest CPP } & initial GCS (0.016) & $3.6(0.7-6.5) \dagger$ \\
\hline & age $(<0.0001)$ & $1.9(0.8-3) \dagger$ \\
\hline & pupils (0.057) & $-5.2(-11.2$ to 0.2$)$ \\
\hline \multirow[t]{3}{*}{$\mathrm{CPP}<40 \mathrm{~mm} \mathrm{Hg}$} & PIM2 (0.001) & $11.2(4.2-17.1) \dagger$ \\
\hline & age (0.004) & $-0.6(-0.9$ to -0.2$) \dagger$ \\
\hline & pupils (0.073) & $1.8(-0.167$ to 3.7$)$ \\
\hline $\begin{array}{l}\text { CPP }<50 \text { mm Hg } \\
\text { systemic hypoxia }\end{array}$ & age $(<0.0001)$ & $-2.4(-3.7$ to -1.1$) \dagger$ \\
\hline $\mathrm{PaO}_{2}<60 \mathrm{~mm} \mathrm{Hg}$ & none & \\
\hline lowest $\mathrm{PaO}_{2}$ & none & \\
\hline $\mathrm{SaO}_{2}<90 \%$ & none & \\
\hline \multicolumn{3}{|l|}{$\mathrm{PbtO}_{2}$} \\
\hline lowest $\mathrm{PbtO}_{2}$ & pupils $(p=0.039)$ & $-3.4(-6.6$ to -0.2$) \dagger$ \\
\hline $\mathrm{PbtO}_{2}<5 \mathrm{~mm} \mathrm{Hg}$ & $\begin{array}{l}\text { initial GCS }(p=0.017) \\
\text { pupils }(p=0.076)\end{array}$ & $\begin{array}{l}-1(-1.8 \text { to }-0.2) \dagger \\
1.6(-0.2 \text { to } 3.4)\end{array}$ \\
\hline $\mathrm{PbtO}_{2}<10 \mathrm{~mm} \mathrm{Hg}$ & pupils $(p=0.057)$ & $5.1(-0.2$ to 10.3$)$ \\
\hline
\end{tabular}

may not always predict whether a pediatric patient will develop secondary cerebral insults after severe TBI.

\section{Glasgow Coma Scale}

The relationship between postresuscitation GCS score and outcome after TBI has been well described. ${ }^{3,6,9,16}$ Given that sedation in the acute phase may influence 2 components of the GCS, (eye opening and verbal responses), the motor component of the GCS is often considered to represent a more reliable assessment. For preverbal children, the pediatric coma scale is preferred. ${ }^{25}$ In a large series of pediatric severe TBI, Ducrocq et al. ${ }^{9}$ reported that a threshold GCS score of 5 or less was associated with mortality and poor outcome. In our study, initial GCS demonstrated an association with different measures of $\mathrm{CPP}$ and $\mathrm{PbtO}_{2}$. However, the GCS score was not associated with various measures of elevated ICP. Furthermore, the motor component of the GCS had no consistent relationships with secondary cerebral insults.

\section{Pediatric Trauma Score}

The PTS is a combined trauma and physiological score developed to predict outcome in pediatric trauma patients. ${ }^{28}$ Its use has been reported in children with TBI, ${ }^{9,12}$ and PTS $<3$ is associated with an increased rate of mortality. 3,12 Although widely used in the assessment of pediatric trauma patients, in this study the PTS failed to correlate with any of the physiological variables known to be associated with secondary insults.

\section{Pediatric Index of Mortality-2}

The PIM2 is used to evaluate patients on admission to the PICU. It is easier to use than Pediatric Risk of Mortality III, which has 17 variables and is used to evaluate patients, not on admission but during the first 24 hours in the PICU. ${ }^{20}$ Although not specifically designed for the evaluation of trauma patients, the PIM2 has been reported to have a close relationship with outcome in pediatric head injury. ${ }^{12}$ We observed that PIM2 was associated with several indices of elevated ICP. However, we did not observe an association between PIM2 and episodes of compromised $\mathrm{PbtO}_{2}$ or systemic hypoxia.

\section{Pupil Reaction}

Pupillary reaction is strongly associated with outcome after TBI. ${ }^{15,30}$ In this study, pupil reaction was associated with $\mathrm{PbtO}_{2}$ and CPP indices, but not with elevated ICP.

\section{Head CT Classification}

There are several classification systems that attempt to relate the initial head CT scan findings to outcome. . $7,7,9,19^{-19}$ The most commonly used system is that developed by Marshall et al. ${ }^{14}$ In this study we observed that the Marshall grade was associated with some indices of ICP, presumably reflecting the association of compressed cisterns and midline shift (diffuse injury Scores III-IV) with ICP. Also, Scores III and IV were associated with craniectomy in univariate analysis, which probably reflects both the scores' association with elevated ICP and the tendency to perform craniectomy in the setting of obliterated cisterns and high ICP. However, we did not observe any association between the Marshall grade and $\mathrm{PbtO}_{2}$ indices, and an association with $\mathrm{CPP}<50 \mathrm{~mm} \mathrm{Hg}$ was found only in univariate analysis.

\section{Patient Age}

In the present study age was related to all indices of CPP. This may reflect the lower physiological thresholds in younger children or the tendency to target higher CPP values with increasing age.

A number of physiological measures had no relationships with acute assessment scores (Table 3). There were also no predictors for treatment variables, except for CT classification with decompressive craniectomy (univariate analysis only).

\section{Methodological Limitations}

There are a number of possible limitations to our study. First, our sample size is relatively small. It is possible that with a larger sample more consistent relationships between the various scores and physiological variables may have been seen. However, we limited the study to 
patients who underwent ICP, CPP, and $\mathrm{PbtO}_{2}$ monitoring. Often only ICP and CPP or blood pressure are evaluated as secondary insults, yet brain hypoxia may occur even when ICP and CPP are adequately managed or even normal, ${ }^{10,27}$ so the addition of $\mathrm{PbtO}_{2}$ as an indicator of possible secondary injury can help detect episodes of secondary injury that may be otherwise undetected. Second, we examined some but not all scores used to classify patients who have suffered TBI. For example, we did not obtain the Injury Severity Score, Head Abbreviated Injury Severity Score, Pediatric Risk of Mortality III, and Relative Head Injury Severity Score. Instead the scores chosen for our study are commonly used in pediatric trauma units and PICUs. Third, the secondary insults we evaluated did not include hypo- or hyperglycemia, pyrexia, seizures, or sepsis. However, the secondary insults chosen for analysis have been extensively reported, and each is known to be associated with adverse outcome after TBI. Fourth, we cannot exclude that prompt identification and treatment of potential secondary insults did not confound our results. However, treatment of patients was not directed by patients' clinical scores. Similar treatment was delivered to all patients. Also, secondary insults in this series were frequent (data not shown); therefore, if there were significant associations between the high-risk scores and the frequency of secondary insults we would have expected to demonstrate them in this cohort.

\section{Conclusions}

We found that acute assessment scores that describe the primary injury sustained by children with severe TBI have a variable relationship with physiological markers of secondary cerebral injury after admission to the PICU. Although we observed associations between individual scores and select measures of secondary cerebral insults, none of the scores evaluated reliably predicted each and every secondary insult. In our opinion, grading systems used to classify initial injury severity, while they may guide initial treatment, appear to have a limited value in predicting who is at risk for secondary cerebral insults. Therefore, clinicians should remain vigilant for the development of secondary insults in all patients who present with significant head trauma.

\section{Disclosure}

Anthony Figaji and Peter LeRoux have received a grant for the study of perfusion pressure thresholds in pediatric traumatic brain injury from the Integra Foundation.

\section{References}

1. Adelson PD, Bratton SL, Carney NA, Chesnut RM, du Coudray $\mathrm{HE}$, Goldstein B, et al: Guidelines for the acute medical management of severe traumatic brain injury in infants, children, and adolescents. Chapter 1: introduction. Pediatr Crit Care Med 4:S2-S4, 2003

2. Ananda A, Morris GF, Juul N, Marshall SB, Marshall LF: The frequency, antecedent events, and causal relationships of neurologic worsening following severe head injury. Executive Committee of the International Selfotel Trial. Acta Neurochir Suppl 73:99-102, 1999
3. Cantais E, Paut O, Giorgi R, Viard L, Camboulives J: Evaluating the prognosis of multiple, severely traumatized children in the intensive care unit. Intensive Care Med 27:1511-1517, 2001

4. Chambers IR, Treadwell L, Mendelow AD: Determination of threshold levels of cerebral perfusion pressure and intracranial pressure in severe head injury by using receiver-operating characteristic curves: an observational study in 291 patients. J Neurosurg 94:412-416, 2001

5. Chesnut RM, Marshall LF, Klauber MR, Blunt BA, Baldwin $\mathrm{N}$, Eisenberg HM, et al: The role of secondary brain injury in determining outcome from severe head injury. J Trauma 34:216-222, 1993

6. Chiaretti A, Piastra M, Pulitano S, Pietrini D, De Rosa G, Barbaro R, et al: Prognostic factors and outcome of children with severe head injury: an 8-year experience. Childs Nerv Syst 18:129-136, 2002

7. Claret Teruel G, Palomeque Rico A, Cambra Lasaosa FJ, Català Temprano A, Noguera Julian A, Costa Clarà JM: Severe head injury among children: computed tomography evaluation as a prognostic factor. J Pediatr Surg 42:1903-1906, 2007

8. Coates BM, Vavilala MS, Mack CD, Muangman S, Suz P, Sharar SR, et al: Influence of definition and location of hypotension on outcome following severe pediatric traumatic brain injury. Crit Care Med 33:2645-2650, 2005

9. Ducrocq SC, Meyer PG, Orliaguet GA, Blanot S, LaurentVannier A, Renier D, et al: Epidemiology and early predictive factors of mortality and outcome in children with traumatic severe brain injury: experience of a French pediatric trauma center. Pediatr Crit Care Med 7:461-467, 2006

10. Figaji AA, Fieggen AG, Argent AC, LeRoux PD, Peter JC: Does adherence to treatment targets in children with severe traumatic brain injury avoid brain hypoxia? A brain tissue oxygenation study. Neurosurgery 63:83-92, 2008

11. Forsyth RJ, Parslow RC, Tasker RC, Hawley CA, Morris KP, UK Paediatric Traumatic Brain Injury Study Group, et al: Prediction of raised intracranial pressure complicating severe traumatic brain injury in children: implications for trial design. Pediatr Crit Care Med 9:8-14, 2008

12. Grinkeviciute DE, Kevalas R, Saferis V, Matukevicius A, Ragaisis V, Tamasauskas A: Predictive value of scoring system in severe pediatric head injury. Medicina (Kaunas) 43:861869,2007

13. Jennett B, Bond M: Assessment of outcome after severe brain damage. Lancet 1:480-484, 1975

14. Marshall LF, Marshall SB, Klauber MR, Van Berkum Clark M, Eisenberg HM, Jane JA, et al: A new classification of head injury based on computerized tomography. J Neurosurg $\mathbf{7 5}$ Suppl:S14-S20, 1991

15. Marshall LF, Smith RW, Shapiro HM: The outcome with aggressive treatment in severe head injuries. Part I: The significance of intracranial pressure monitoring. J Neurosurg 50:20-25, 1979

16. Martin C, Falcone RA Jr: Pediatric traumatic brain injury: an update of research to understand and improve outcomes. Curr Opin Pediatr 20:294-299, 2008

17. Morrison WE, Arbelaez JJ, Fackler JC, De Maio A, Paidas $\mathrm{CN}$ : Gender and age effects on outcome after pediatric traumatic brain injury. Pediatr Crit Care Med 5:145-151, 2004

18. Pigula FA, Wald SL, Shackford SR, Vane DW: The effect of hypotension and hypoxia on children with severe head injuries. J Pediatr Surg 28:310-314, 1993

19. Pillai S, Praharaj SS, Mohanty A, Kolluri VR: Prognostic factors in children with severe diffuse brain injuries: a study of 74 patients. Pediatr Neurosurg 34:98-103, 2001

20. Pollack MM, Patel KM, Ruttimann UE: PRISM III: an updated pediatric risk of mortality score. Crit Care Med 24:743752,1996

21. Salorio CF, Slomine BS, Guerguerian AM, Christensen JR, 


\section{Acute clinical scores and secondary cerebral insults in children}

White JR, Natale JE, et al: Intensive care unit variables and outcome after pediatric traumatic brain injury: a retrospective study of survivors. Pediatr Crit Care Med 9:47-53, 2008

22. Samant UB, Mack CD, Koepsell T, Rivara FP, Vavilala MS: Time of hypotension and discharge outcome in children with severe traumatic brain injury. J Neurotrauma 25:495-502, 2008

23. Sharples PM, Storey A, Aynsley-Green A, Eyre JA: Avoidable factors contributing to death of children with head injury. BMJ 300:87-91, 1990

24. Signorini DF, Andrews PJ, Jones PA, Wardlaw JM, Miller JD: Adding insult to injury: the prognostic value of early secondary insults for survival after traumatic brain injury. J Neurol Neurosurg Psychiatry 66:26-31, 1999

25. Simpson DA, Cockington RA, Hanieh A, Raftos J, Reilly PL: Head injuries in infants and young children: the value of the paediatric coma scale. Review of literature and report on a study. Childs Nerv Syst 7:183-190, 1991

26. Slater A, Shann F, Pearson G, Paediatric Index of Mortality (PIM) Study Group: PIM2: a revised version of the paediatric index of mortality. Intensive Care Med 29:278-285, 2003

27. Stiefel MF, Udoetuk JD, Spiotta AM, Gracias VH, Goldberg A, Maloney-Wilensky E, et al: Conventional neurocritical care and cerebral oxygenation after traumatic brain injury. J Neurosurg 105:568-575, 2006

28. Tepas JJ III, Ramenofsky ML, Mollitt DL, Gans BM, DiScala C: The pediatric trauma score as a predictor of injury severity: an objective assessment. J Trauma 28:425-429, 1988

29. Valadka AB, Gopinath SP, Contant CF, Uzura M, Robertson CS: Relationship of brain tissue PO2 to outcome after severe head injury. Crit Care Med 26:1576-1581, 1998

30. van Dongen KJ, Braakman R, Gelpke GJ: The prognostic value of computerized tomography in comatose head-injured patients. J Neurosurg 59:951-957, 1983

31. Vavilala MS, Bowen A, Lam AM, Uffman JC, Powell J, Winn $\mathrm{HR}$, et al: Blood pressure and outcome after severe pediatric traumatic brain injury. J Trauma 55:1039-1044, 2003

Manuscript submitted June 15, 2008.

Accepted August 14, 2008.

Address correspondence to: Anthony A. Figaji, F.C.S., 617 Institute for Child Health, Red Cross War Memorial Children's Hospital, Klipfontein Road, Rondebosch, 7700 Cape Town, South Africa. email: Anthony.Figaji@uct.ac.za. 